Relations industrielles

Industrial Relations

\title{
De la prévision économique à la gestion financière, par Jacques Gervais, Paris, Entreprise Moderne d'Édition, 1970, 351 pp.
}

\section{Jean-Pierre Beaulieu}

Volume 26, numéro 2, 1971

URI : https://id.erudit.org/iderudit/028236ar

DOI : https://doi.org/10.7202/028236ar

Aller au sommaire du numéro

Éditeur(s)

Département des relations industrielles de l'Université Laval

ISSN

0034-379X (imprimé)

1703-8138 (numérique)

Découvrir la revue

Citer ce compte rendu

Beaulieu, J.-P. (1971). Compte rendu de [De la prévision économique à la gestion financière, par Jacques Gervais, Paris, Entreprise Moderne d’Édition, 1970, 351 pp.] Relations industrielles / Industrial Relations, 26(2), 516-516.

https://doi.org/10.7202/028236ar

Tous droits réservés @ C Département des relations industrielles de l'Université Laval, 1971
Ce document est protégé par la loi sur le droit d'auteur. L’utilisation des services d'Érudit (y compris la reproduction) est assujettie à sa politique d'utilisation que vous pouvez consulter en ligne.

https://apropos.erudit.org/fr/usagers/politique-dutilisation/ 
section syndicale de l'entreprise et les attitudes nouvellement acquises de la maîtrise à l'endroit des pratiques à adopter dans ses relations avec les ouvriers et les employés. D'une part, les directions cherchent à garder jalousement leur autorité en maintenant à distance, en harcelant, en menaçant même les délégués de personnel et la section syndicale. D'autre part, la maîtrise sert de tampon où s'isole à la fois la direction et les ouvriers en cherchant, par un savoirvivre et un savoir-faire fraîchement acquis, à atténuer le poids et l'ommiprésence de l'autorité.

C'est là le type de contradictions auxquelles nous faisions allusion plus haut et qui semblent inhérents à un effort d'intégration des travailleurs dans l'entreprise. Chaque cas étudié révèle un degré d'intégration plutôt faible, plus marqué par le conflit ouvert ou larvé que par l'harmonie au sein des rapports sociaux. Au risque d'errer, nous croyons qu'un enseignement se dégage de cette étude, un enseignement que la plupart des directions ont tendance à oublier. Le développement d'un climat de relations interpersonnelles authentiques nous semble impossible dans une entreprise où la direction cherche à démolir l'institution syndicale ou refuse «d'avoir les coudées franches 》 avec les représentants des différentes catégories de personnel.

\section{Laurent BELANGER}

\section{De la prévision économique à la gestion}

financière, par Jacques Gervais, Paris, Entreprise Moderne d'Edition, 1970, $351 \mathrm{pp}$.

Dans ce volumineux ouvrage, l'auteur traite de l'influence de la prévision économique sur la gestion financière dans trois domaines qu'il assigne à la gestion financière: l'orientation générale des investissements; le calcul économique des solutions les plus avantageuses; le financement des investissements.

Dans chacun de ces domaines, son étude porte successivement sur la gestion financière de l'Etat, élément de l'environnement économique, et la gestion financière de l'entreprise, compte tenu de cet environnement.

Ce volume s'adresse d'abord et plus particulièrement à des lecteurs français car l'auteur désire, par son ouvrage, in- téresser et enseigner les cadres et les spécialistes financiers de France sur la gestion prévisionnelle, technique pour mieux orienter les investissements et la marche des entreprises de façon à atteindre le niveau de rentabilité que connaissent les entreprises américaines.

L'ouvrage est cependant d'intérêt pour quiconque s'intéresse à ces questions, et plus particulièrement aux techniques de l'analyse financière que l'auteur étudie longuement dans la deuxième partie. Les explications sont de telle nature qu'il n'est pas nécessaire d'être un spécialiste pour les aborder et en tirer profit, toutefois même un spécialiste pourra y retrouver ses notions théoriques de base et retracer l'élément qu'il avait oublié.

Jean-Pierre BEAULIEU

\section{Comment concevoir un système intégré de gestion, par P. J. Yvon et C. Semin, Paris, Entreprise Moderne d'Edition, $1970,260 \mathrm{pp}$.}

La plupart des ouvrages sur l'utilisation intensive et systématique de l'ordinateur en administration des entreprises sont en anglais. Les Entreprises modernes d'édition, avec le concours des auteurs P.J. Yvon et C. Semin, tous deux ingénieurs à Dubold-France, viennent de mettre sur le marché cet ouvrage en français sur les systèmes intégrés de gestion (Integrated Management Information System). C'est l'intégration en un seul système des applications, existantes et à concevoir, du traitement automatique des données à la gestion de l'entreprise.

Les deux auteurs en partant de leur expérience personnelle et des théories existantes ont dégagé les principes et les modalités de mise en œuuvre d'un système intégré.

Dans ce type de système, les données ne sont saisies qu'une seule fois pour être traitées automatiquement dans plusieurs programmes correspondant à des objectifs différents. En d'autres mots, des services ou des unités administratives différentes qui utilisent une information de base identique touchant l'accomplissement d'une activité devraient se concerter pour cueillir les données et les entrer dans l'ordinateur sans faire une duplication. Ce principe amène les auteurs à préciser la signification d'une 